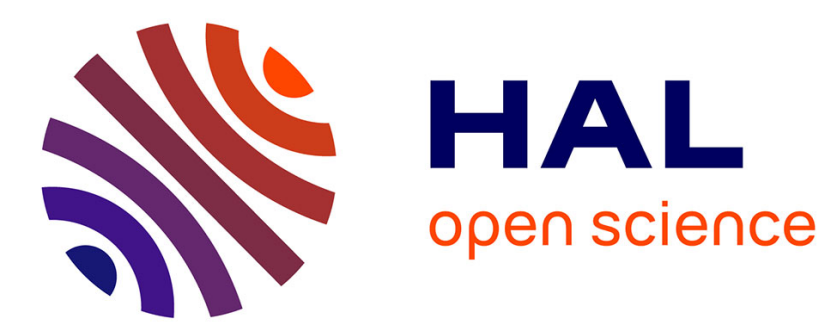

\title{
Open areas of vibrating lips in trombone playing
}

Seona Bromage, Murray Campbell, Joël Gilbert

\section{To cite this version:}

Seona Bromage, Murray Campbell, Joël Gilbert. Open areas of vibrating lips in trombone playing. 2010. hal-00474644

\section{HAL Id: hal-00474644 https://hal.science/hal-00474644}

Preprint submitted on 21 Apr 2010

HAL is a multi-disciplinary open access archive for the deposit and dissemination of scientific research documents, whether they are published or not. The documents may come from teaching and research institutions in France or abroad, or from public or private research centers.
L'archive ouverte pluridisciplinaire HAL, est destinée au dépôt et à la diffusion de documents scientifiques de niveau recherche, publiés ou non, émanant des établissements d'enseignement et de recherche français ou étrangers, des laboratoires publics ou privés. 


\title{
Open areas of vibrating lips in trombone playing
}

\author{
Seona Bromage* , Murray Campbell ${ }^{*}$ and Joël Gilbert ${ }^{\dagger}$ \\ *School of Physics and Astronomy, University of Edinburgh, U.K. \\ †Laboratoire d'Acoustique de l’Université du Maine, UMR CNRS 6613, Le Mans, France
}

\begin{abstract}
In brass instruments the player's lips are used as a control valve that allows an oscillating flow of air into the instrument. The behaviour of this valve, the lip-reed, is determined by both the pressure difference across the lips and the open area between the lips. Computer simulations of brass instrument playing frequently represent the lips as an oscillating system with one degree of freedom, representing the height of the lip opening. This study aims to provide experimental evidence to determine values of an exponential coefficient $q$ defining the area-height function for the lips of trombone players. A high speed digital video camera and transparent mouthpiece have been used to produce detailed images of the motion of the vibrating lips of a range of musicians and an artificial mouth over a large set of playing frequencies and sound levels. These images are analysed to investigate how the open area varies as a function of the height between the lips.
\end{abstract}

\section{Introduction}

Sound production in reed and brass instruments is the result of self-sustained oscillations. A mechanical oscillator, the reed, acts as a valve which modulates the air flow entering the mouthpiece. The nature of the motion of the brass player's lips determines the flow of air through the lips from the player's mouth into the instrument. Thus, in brass instruments the flow control mechanism depends on the open area $S$ between the player's lips. In computer simulations of brass instrument playing, the lips are frequently modelled as an oscillating system with one degree of freedom, representing the height $h$ of the lip opening. For the single-reed instruments, the width of the flow control aperture is approximately constant, implying a simple linear relationship between $S$ and $h$. This constant width approximation is not generally valid for the flow control aperture in a brass instrument; as a consequence, a sinusoidal variation in the lip height does not necessarily imply an equally simple sinusoidal variation in open area. The main objectives of this paper are to describe experimental investigations of the variation of the open area as a function of the height of the lip opening in brass instrument playing, and to propose an empirical area-height function through which simulations using a one degree of freedom lip model can be made more realistic.

Several previous studies [1, 2, 3, 4] have used photographic techniques to visualise the motion of brass players' lips. Elliott and Bowsher [5] have used measurements of mouth pressure and average flow to calculate average values of lip opening for both trombone and trumpet. Recent developments of artificial mouths have led to studies $[6,7,8,9]$ which have used optical techniques 
to measure the opening between the artificial lips during self oscillation as well as when acoustically driven. Martin [1] and Copley and Strong [2] both presented plots of lip separation against open area; Martin concluded that at high frequencies the area was nearly proportional to the lip central separation, but that the ratio was not constant for large amplitude lower frequency notes. Copley and Strong reported an almost linear relationship between the area and height. None of these previous studies have given quantitative information on the form of the function, $S(h)$, which relates these two variables.

Here high speed digital photography is used to image the self-oscillating lips of trombone players. The primary objective is to investigate variations in the opening between the lips over a wide range of pitches and sound levels, using a number of different players. The oscillation behaviour of a set of artificial lips has also been studied. One aim of this work is to make a comparison of the behaviour of the artificial lips with that of real musicians and hence to provide evidence of the validity of the use of the artificial mouth as a model for real brass players. This investigation also aims to provide experimental evidence to aid the process of refining physical models of the behaviour of the brass player's lips, and hence the development of more accurate simulations of brass instruments. One specific aim is to give quantitative information on the form of the area-height function $S(h)$.

The present paper begins with a summary of reed and brass instrument modelling (Section 2). This is followed by a description of the experimental and analysis techniques used, and of experimental observations of lip opening cycles (Section 3). In Section 4 the results are discussed using a definition of a power law function relating area and height which is useful in modelling. From an analysis of a large number of experimental observations it has been possible to extract typical values of the exponent $q$ of the power law function, and to explore quantitatively its variation with the pitch and sound level of the played notes.

\section{Modelling reed and brass instruments}

\subsection{Elementary global model}

The basic physics of brass instruments under playing conditions can be described by an acoustic model adapted from Elliott and Bowsher [5] and detailed in Cullen et al [7]. The acoustic model can be summarised as a system of three equations, which are function of three periodic variables: the height $h(t)$ of the opening between the two lips of the player, the volume flow $u(t)$ at the entrance to the mouthpiece, and the mouthpiece acoustic pressure $p(t)$. The lips act as a valve controlling the air flow from the mouth (at pressure $P_{m}$ ) into the instrument mouthpiece; this flow depends both on the pressure drop $\Delta p=P_{m}-p(t)$, and on the open area $S(t)$. The behaviour of the valve can be described by a non-linear equation of the form

$$
u(t)=S(t) \sqrt{\frac{2\left(P_{m}-p(t)\right)}{\rho}} .
$$

$S(t)$, the open area of the lips, can be represented as $S(t)=h(t) b(t)$, where $b(t)$ is an effective width of the lip opening; in wind instrument simulations the model is often simplified by taking $b$ to be constant (see for example Hirschberg et al. [10]). The opening height $h(t)$ varies around a rest value $h_{o}$ which is characteristic of the brass player's embouchure. The simplest model of the lip motion 
is based on a one degree of freedom mechanical system represented by the following equation:

$$
\ddot{h}+\alpha \dot{h}+\omega_{r}^{2}\left(h-h_{o}\right)=-\frac{\Delta p}{\mu}
$$

where $\alpha$ is the lip damping coefficient, $\omega_{r}$ is the lip natural resonance frequency, and $\mu$ is an effective mass per area parameter of the lips.

In the quasi-static case, for which $\ddot{h}$ and $\dot{h}$ can be neglected, Equation 2 implies that an increase of $\Delta p$ results in a decrease of the lip opening $h-h_{o}$; this kind of valve is often called an "inward striking reed" $[11,12,13]$. Reversing the sign of the term on the right hand side of Equation 2 implies an opening of the lip aperture in response to a quasi-static increase in $\Delta p$; this is the characteristic behaviour of an "outward striking reed".

Equations 1 and 2 represent the non-linear aeroelastic valve which is coupled with the air column. The acoustic volume flow and the acoustic pressure in the mouthpiece are related through the acoustic resonator, which in the linear approximation can be represented by the input impulse response $g(t)$ in the time domain (Equation 3), or by its Fourier transform the input impedance $Z_{\text {in }}(\omega)$ in the frequency domain (Equation 4):

$$
\begin{gathered}
p(t)=\int g(t) * u(t) \\
Z_{\text {in }}(\omega)=\frac{p(\omega)}{u(\omega)}
\end{gathered}
$$

The input impedance of a brass instrument exhibits several resonance peaks: around ten for a trumpet or a trombone, more than fifteen for a french horn. By changing the configuration of the embouchure, the wind instrument player is able to obtain different periodic regimes, for each of which the fundamental frequency is normally close to one of the resonance frequencies of the instrument. Players of cane reed instruments use register holes in the resonator to help them to overblow to the second and third regimes. Because of the much greater flexibility of the lip-reed, the experienced brass player can get more than eight regimes without any register hole.

The plane-wave approximation is commonly used to describe linear propagation in pipes, and is capable of explaining a large class of phenomena in wind instrument acoustics. Nevertheless this approximation becomes questionable for high frequencies, or for horns having widely flaring bells. Then more sophisticated theories, such as multimodal approaches, are required (see [14]).

The elementary model based on Equations 1, 2 and 4 is well adapted to find numerical solutions of the steady self-sustained oscillations of brass instruments using the harmonic balance technique [15]. In order to carry out the simulations, values of the parameters used in the model are needed. Although the brass instrument resonator is well described by its input impedance which is known, providing the lip parameters needed in Eq.1 and 2 is not an easy task: the lip parameters used in simulations can be adapted from ones available in the literature.

The steady state solutions $p(t)$ coming from the elementary model correspond to the instrument mouthpiece acoustic pressure. However, external acoustic pressures are needed in order to be comparable with recorded tones. The concept of "spectrum transformation function" is then useful. According to Benade's theory [16], the general trend of the spectrum transformation function $T(j \omega)$ relating the external pressure amplitudes of the various harmonics to the internal pressure amplitudes is a linear relationship varying from 0 to 1 as the frequency increases from $0 \mathrm{~Hz}$ to a cut-off 
frequency $f_{c}$ characteristic of the instrument; above $f_{c}, T(j \omega)$ is assumed to be equal to 1 , the spectrum transformation function representing an ideal high-pass filter.

\subsection{Opening areas of vibrating reeds}

The simplification that the open area of a vibrating reed can be defined as $S(t)=h(t) b$, where $b$ is a constant effective width, seems to be very well adapted to single reed wind instruments such as the clarinet and saxophone (see for example [17, 18]). The experimental investigations described in this paper show that for the brass player's lips the relationship between the opening area $S(t)$ and the opening height $h(t)$ cannot in general be described by this simple linear law. In order to make use of the elementary model described previously, in which the mechanical behaviour of the valve is described by a one degree of freedom lumped model (see Equation 2), the complicated behaviour of the area $S(t)$ of the lip opening has to be represented in terms of the height $h(t)$ of the opening. The basic idea of this paper is to test the hypothesis that the area-height function for the vibrating lips of a brass player can be represented by a power law of the form

$$
S(t)=S_{o}\left(\frac{h(t)}{h_{o}}\right)^{q}
$$

where $S_{o}$ and $h_{o}$ are reference values of the lip opening area and height respectively, and $q$ is an exponent to be determined.

Because of the geometry of the double-reed entrance of oboes or bassoons (see for example Figure 1 of [19]), a power law with an exponent $q$ greater than 1 could be expected for double reed woodwind instruments. Surprisingly, some recent experimental results [20] show a linear behaviour, implying $q=1$. Msallam [21] assumed a quadratic relationship $(q=2)$ in a lip model for sound synthesis of trombones; this assumption was based on visualisations showing that the effective oscillating width of the lip opening increases with increasing aperture (see [2] for example).

Figure 1 illustrates schematically how different types of aperture area variation are reflected in the magnitude of the exponent $q$ : (1) a "moving rectangular area", (2) a "moving diamond" area, (3) a "moving circle" area. The first case obviously corresponds to linear behaviour $(q=1)$; the second case corresponds to quadratic behaviour $(q=2)$. For the third case, it can be shown that the open area $S$ can be expressed as $S=2 R^{2}[\alpha-\sin (\alpha) \cos (\alpha)]$; numerical fitting yields $q=1.5$, an intermediate case between linear and quadratic.

\section{Experimental investigation of lip motion}

\subsection{Experimental procedure}

A transparent trombone mouthpiece (see Figure 2) developed by Richards [9] was used to allow the lips to be visualised. The perspex mouthpiece follows a cylindrical design by Ayers [22]; the rim and throat dimensions are those of a Denis Wick 6BS tenor trombone mouthpiece. The cylindrical cup is closed by a flat optical glass window perpendicular to the cylinder axis, allowing an unobstructed view of the lip opening. The shank of the mouthpiece emerges from the side of the cylindrical cup. It is important that the rim measurements were kept the same as the reference mouthpiece so as 
to provide the 'correct feel' to the players. The other dimensions were chosen primarily to allow for the robust connection of the shank to the cup. This resulted in the volume of the transparent mouthpiece being, at $12 \mathrm{ml}$, slightly larger than the reference mouthpiece; it consequently has a lower frequency impedance peak [9]. The mouthpiece is reported (by musicians) to play especially well for the lower regimes, though slightly less well for the higher modes. A King tenor trombone was used for the majority of the experiments.

For all experiments the lip motion was filmed using a high speed digital camera (Vision Research, Inc. [23] Phantom v4.1). This allowed a typical capture rate of 5000 frames per second. Image size was generally 512 by 64 pixels for the artificial lips, and 256 by 64, or 128 by 128 for the musicians.

The high frame rate necessitates a short exposure time and therefore requires the use of a strong light source. A Schott KL1500 LCD swan-neck lamp was used; this had the benefit of being a cool source, and so was suitable for use within close proximity to the musicians. The maximum possible exposure time for this frame rate $(180 \mu \mathrm{s})$ was used; however it was still necessary to use a relatively large aperture on the camera lens to allow in enough light. This requirement had to be balanced with the need for a reasonable depth of focus to optimise image quality and to avoid the lips moving in and out of focus as they moved in the direction perpendicular to the plane of the image.

For the experiments with the artificial lips, the mouth used was based on the design developed by Cullen [7], and modified by Richards [9]. The embouchure was controlled by adjusting the internal lip water pressure, the position of the lip guides and the amount of pressure exerted on the lips by the mouthpiece. For these experiments the embouchure was set and then the note sounded at a moderate to high mouth pressure for several minutes in order to ensure that the embouchure was stable. Because it is difficult to obtain low notes with this artificial mouth, the range of playing frequencies investigated was limited to $150 \mathrm{~Hz}-220 \mathrm{~Hz}$.

Whilst the embouchure of the artificial mouth is on the whole largely symmetrical and the opening easily visualised, this is not the case for many human players. With several musicians there was difficulty in visualising part or all of the opening between the lips due to 'overhang' of the top lip. This was more significant with some players than others, and was particularly a problem with high notes where the amplitude of oscillation is small and the overhang increased. Similar difficulties have been noted in previous studies $[1,2]$. The visualisation could be improved by adjusting the camera angle for each new embouchure, but in practice this problem limited the upper range of notes which could be investigated.

The images recorded by the camera with the setup described above represent the projection of the lip opening on a plane perpendicular to the direction of view, which was close to the direction of air flow through the lips. In subsequent experiments the direction of view was rotated through $90^{\circ}$ to record the lip motion in a plane containing the direction of flow [24]. These results confirmed those of previous studies [2,4] showing that the motion of the lips in brass instrument playing has in general an important component in the direction of flow, with frequent evidence of transverse waves on the lips. For the purposes of the present study, which attempts to relate observed lip behaviour to a simplified one degree of freedom model, the three dimensional nature of the lip motion was ignored, and $S(h)$ and $h$ were measured from the images taken with the camera directly in front of the lips.

Five human players took part in the experiments. All were amateur or semi-professional musicians with many years of experience in both orchestral performance and other musical genres. The players were asked to sound the notes notes $\mathrm{B} b_{1}, \mathrm{~B} b_{2}, \mathrm{~F}_{3}$, and $\mathrm{D}_{4}$ or $\mathrm{F}_{4}$ at a range of levels, nominally $p$, 
$m f$, and $f$ or $f f$. The upper limit of pitches that were possible to analyse depended greatly on the player and the dynamic level played. The measurements were carried out in a normal laboratory. The level of the radiated sound was measured with a Cel D-1422 Sound Level Meter on the axis of the bell at a distance of one bell radius. Players were asked to play a note of approximately three seconds duration and the camera was triggered manually to capture part of the steady state of each note. For the measurements with real players it was necessary to apply a low-surface tension liquid (for example a liquid soap such as Teepol) to the inside of the optical viewing window of the mouthpiece. This was to prevent the moisture from the player's breath from condensing on the surface and obscuring the view of the lips.

\subsection{Analysis of images}

Each of the high speed digital films was edited to give a series of images, typically 200 frames, including several cycles of oscillation of the lips. These individual frames were cropped to leave just the area of interest, thus reducing the data size and hence the analysis time. Figure 3 shows examples of images obtained from one cycle of lip vibration.

Each series of images was then analysed in Matlab using a script designed with a Graphical User Interface. The interface allowed viewing of the original image alongside a 'thresholded' image, whilst adjusting the threshold value. By this process a pixel threshold level was manually chosen to isolate the open area from the lip images. The value varied from one data set to another due to variations in the quality of the lighting, including the presence or absence of shadows on images and teeth visible within the open area. In some extreme cases it is necessary to manually 'correct' the images containing particularly obvious teeth.

Following the selection of the threshold level, further analysis steps were carried out using code also written in Matlab. Using a loop, each image in the series was examined in turn. For each image a further loop looked at each pixel column by column and compared the value to the chosen threshold level. For each pixel determined to be 'open' (ie darker than the threshold) the area count was increased. The open height at each column was determined to be the count of the number of 'open' pixels in that column; from this the maximum and mean height of the open area in the image were calculated. Similarly the width was determined to be the number of rows containing an open pixel. A count of the total number of open pixels was also obtained for each image, before moving on to the next image in the series. After all images were analysed this resulted in data for the maximum and mean heights, width, and total area (in pixels) as a function of frame number. A calibration image taken using graph paper wrapped around the lip of the player was used to obtain the number of pixels per mm.

\subsection{Uncertainties in measurements}

For high pitch, low sound level notes, the overhang of the top lip can be significant, and this reduces the reliability of the data for the opening part of the lip vibration cycle. It is hard to quantify the effect of this issue, but it is estimated that this is the most significant source of error in the measurements of the smallest amplitude lip openings.

Variations in embouchure, and in some cases the constraints of the experimental setup, can result in the image boundaries being not aligned exactly with the lip opening. In most cases the alignment is 
within a few degrees, and even the worst examples are at most rotated by $12^{\circ}$ from alignment. As the analysis procedure measures width horizontally and height vertically within the image boundaries, any misalignment is a source of error in the measurements obtained. In most cases the correction factor is very small, and even in the worst examples (rotated by $12^{\circ}$ from alignment) this equates to a $2 \%$ over estimate of height and $2 \%$ under-estimate of width. The area measurements are unaffected.

The choice of threshold value in the image analysis affects the exact areas and heights measured, as the lip edges are not a sudden change from black to white but shades of grey. This is obviously more significant for small openings than large. The uncertainty in the linear measurements (maximum height and width) due to this cause is estimated to be \pm 1 pixel, which is equivalent to between \pm $0.06 \mathrm{~mm}$ and $\pm 0.121 \mathrm{~mm}$. The conversion from pixels to length introduces a further uncertainty of the order of $2 \%$. Taking into account the various sources of uncertainty, the linear measurements (height and width) are estimated to be accurate to the nearest $0.2 \mathrm{~mm}$, and the area measurements to the nearest $1 \mathrm{~mm}^{2}$.

\subsection{Observed features of lip vibration}

The variable $h(t)$ used to describe the lip motion is Section 2 is frequently associated with the maximum lip separation. This is reasonable if the vibrations of the lips display behaviour which is essentially a modulation of the vertical scale of the aperture. However as can be seen in the example given in Figure 3, the brass player's lips undergo very complicated movements, where often the maximum height is not an appropriate measure of the overall lip separation. In this case it is more useful to associate $h(t)$ with the mean height, averaged over the width of the lip opening. This effectively simplifies a complicated shape where different sections of the lips are moving in different ways to a rectangle of time varying width and height (see Figure 4).

This definition results in an improvement in height resolution and produces more detail in the areaheight plot. Curves are also generally more regular showing in particular a reduction in the deviation from a straight line at high amplitudes. This appears to be due to specific behaviour during this portion of the cycle where the 'tip' of the lip often moves quite dramatically, so causing the maximum height to vary much more significantly than the mean height. The mean height definition of $h(t)$ is therefore adopted for the remainder of this study.

Many insights can be gained from qualitative and quantitative descriptions of the characteristics of lip motion of the brass player. The observed motion of the lips is often seemingly very complex with motion both in the plane of the lip opening and perpendicular to that plane. It is necessary to make certain simplifications in order to enable quantitative descriptions of the observed behaviour. Visual inspection of the raw films often suggests the presence of secondary transverse waves moving along the lip and other higher order oscillations, investigation of which is beyond the scope of this study. Here, only the two-dimensional motion in the plane of the lip opening is described. First the time-averaged behaviour is presented; this is followed by the results of analysis of variations within each cycle.

\section{Time-averaged behaviour}

Previous studies have noted that the amplitude of lip motion increases with increasing sound level but decreases with increasing frequency $[1,2,5]$. Inspection of the raw films taken in the present 
study showed considerable diversity in the lip vibration patterns of the five trombonists, but confirmed the general tendency reported by Yoshikawa and Muto in their study of five horn players [4] for the vibration amplitude in the plane of the lip opening to decrease with increasing pitch of the note played.

One characteristic parameter of an embouchure is the time averaged lip separation $h_{0}$, calculated from the time average of the lip opening mean height over a number of complete cycles. Table 1 gives time-averaged values of the measured lip separation as a function of frequency for notes played by a number of players. For each measurement (a single note by a single player) the value of the mean lip separation, $h_{0}$, was calculated over an integer number of complete cycles of oscillation. Then, using results from five different players, the average was calculated for each note of the same pitch and nominal dynamic level (for example $\mathrm{B} b_{1} m f$ ). Bearing in mind that interpretation of the dynamic level was a musical judgment by the player, it is unsurprising that there were significant differences between the results from different players; however, the averaged magnitudes and the trends of their variation with frequency and sound level are in broad agreement with previous studies $[1,5,2]$.

Table 1: Time averaged lip separation $h_{0}$ (Average values for the five players)

\begin{tabular}{|l|l|l|}
\hline Note & Dynamic & $h_{0}(\mathrm{~mm})$ \\
\hline $\mathrm{B} b_{1}$ & $f f$ & 2.0 \\
$\mathrm{~B} b_{2}$ & $f f$ & 1.5 \\
$\mathrm{~F}_{3}$ & $f f$ & 1.3 \\
$\mathrm{D}_{4}$ & $f f$ & 1.4 \\
$\mathrm{~F}_{4}$ & $f f$ & 0.6 \\
\hline $\mathrm{B} b_{1}$ & $m f$ & 1.4 \\
$\mathrm{~B} b_{2}$ & $m f$ & 0.8 \\
$\mathrm{~F}_{3}$ & $m f$ & 0.7 \\
$\mathrm{D}$ & $m f$ & 0.3 \\
\hline $\mathrm{B} b_{1}$ & $p$ & 1.0 \\
$\mathrm{~B} b_{2}$ & $p$ & 0.5 \\
$\mathrm{~F}_{3}$ & $p$ & 0.7 \\
\hline
\end{tabular}

\section{Variation of lip opening with time}

Figure 5 shows graphs of area, height and width of the lip opening as a function of time for one player (AJ) sounding the four notes $\mathrm{B} b_{1}, \mathrm{~B} b_{2}, \mathrm{~F}_{3}$, and $\mathrm{F}_{4}$ at the same dynamic level $m f$. The data for the height and area of the lip opening show generally smooth variations over the course of each cycle of oscillation. The width of the opening varies less smoothly, with regions of almost constant value at maximum opening for the low frequency notes. The lips close, or almost close, once during each cycle, and the motion is approximately sinusoidal in agreement with previous studies [1, 2]. The results show the expected decrease in amplitude with increasing frequency of the note played.

Figure 6 shows the width of the lip opening of a human musician and an artificial mouth as a function of time for different dynamic levels. The results from the musician (in the upper part of the figure) show that the proportion of the cycle where the width is approximately constant varies from $80 \%$ 
at $f f$, to $74 \%$ at $m f$ and down to $49 \%$ for the quietest level, $p p$. The results from the artificial mouth (in the lower part of the figure) show similar periods of constant width but the extent to which this varies with sound level is less clear.

It is likely that the rim of the mouthpiece has a constraining effect on the lips which is responsible for the saturation of the lip opening width. For the lowest pitched loudest notes, the maximum width is close to the internal diameter of the mouthpiece, $25 \mathrm{~mm}$. For higher pitched notes, the amount of lip present within the rim of the mouthpiece is usually greater, and the lip tension is also increased, meaning that the maximum possible width will be smaller. Often the lip opening is displaced vertically from the centre of the mouthpiece so that the internal space is less than $25 \mathrm{~mm}$. Two example images showing the maximum width of the lip opening are given in Figure 7 . In general, the more homogeneous artificial lips are more consistent in terms of the lip width variation than are the lips of human players.

\section{The area-height function}

\subsection{Fitting procedure}

The power law function defined in Section 2, Equation 5 was introduced as a hypothetical way of representing the variation of the area of the lip opening with the opening height. The validity of this hypothesis has been tested using the results obtained from a number of human performers and an artificial mouth as described in Section 3. For each note analysed, a log-log plot was made of area $S(t)$ against mean height $h(t)$. If the area-height function has the form of Equation 5 it should be possible to fit a straight line to the data on the log-log plot; the gradient of this line will give the value of the exponent $q$.

An example plot is shown in Figure 8. In this case results for the note E3 played at two different dynamic levels by the artificial mouth are displayed. Good straight line fits can be made to both sets of results; the $q$ values of 1.49 at $85 \mathrm{~dB}$ and 1.55 at $103 \mathrm{~dB}$ are almost identical.

Many data sets have 'noise' present at very low amplitudes due to the low accuracy achievable when imaging very small regions of lip opening. Where the lip separation is less than $0.2 \mathrm{~mm}$ and equivalent to only 1 or 2 pixels the error is of the same order as the measurement itself and therefore this data is excluded before fitting a straight line.

Some data sets do not support a single straight line fit over the full range of heights and areas. In particular some low pitched notes played by human musicians at moderate to high sound levels show a distinct change in the gradient at a particular value of $h(t)$. In addition a small number of results show significant hysteresis, giving two distinct lines of data corresponding to the opening and closing phases of the cycle. The results for the artificial mouth in general show more simple behaviour, with little hysteresis or variations in the gradient within a single data set.

Section 4.2 discusses results from plots in which a single value of $q$ is found to give a reasonably good representation of the area-height function over most of the vibration cycle. In Section 4.3 cases for which the area-height function cannot be adequately represented by a single straight line on the log-log plot are considered. 


\subsection{Single-exponent area-height functions}

Three data sets are presented in Figure 9, showing results for the note $\mathrm{B} b_{1}$ played by musician $\mathrm{AJ}$ at three dynamic levels: $f f$ (top), $m f$ (middle) and $p$ (bottom). At the $p$ level, the overall behaviour can be well approximated by a single straight line with $q=1.8$ over the entire height range $(0.25 \mathrm{~mm}$ to $1.5 \mathrm{~mm})$. For the $m f$ and $f f$ notes, most of the height range $(0.6 \mathrm{~mm}$ to above $3 \mathrm{~mm})$ can be represented by straight lines with $q=1.2$ and 0.95 respectively. The smallest openings clearly follow a different law, with higher mean values of $q$ and greater scatter.

Though there are differences in the exact values of the exponent $q$ between players, the behaviour of player AJ is typical of all the musicians investigated. Values of $q$ range from just below 1 to over 2 .

Table 2: Single $q$ values for player AJ (valid for $h>0.25 \mathrm{~mm}$ at $p, h>0.6 \mathrm{~mm}$ at $m f$ and $f f$ )

\begin{tabular}{|l|l|l|l|}
\hline Note & Dynamic & level $(\mathrm{dB})$ & $q$ \\
\hline $\mathrm{B} b_{1}$ & $f f$ & 110 & 0.95 \\
$\mathrm{~F}_{4}$ & $f f$ & 127 & 1.8 \\
\hline $\mathrm{B} b_{1}$ & $m f$ & 98 & 1.2 \\
$\mathrm{~B} b_{2}$ & $m f$ & 95 & 1.3 \\
$\mathrm{~F}_{3}$ & $m f$ & 97 & 1.6 \\
$\mathrm{~F}_{4}$ & $m f$ & 109 & $1.9(1.5-2.5)$ \\
\hline $\mathrm{B} b_{1}$ & $p$ & 83 & 1.8 \\
$\mathrm{~B} b_{2}$ & $p$ & 86 & 1.7 \\
$\mathrm{~F}_{3}$ & $p$ & 87 & 1.8 \\
$\mathrm{~F}_{4}$ & $p$ & 100 & 2.4 \\
\hline
\end{tabular}

Table 2 summarises the variation of $q$ with pitch and dynamic level for player AJ. As the pitch of the played note rises the value of the exponent $q$ increases. At $m f$ level the value of the exponent $q$ increases with rising pitch from close to 1 for the note $\mathrm{B} b_{1}$ to close to 2 for the note $\mathrm{F}_{4}$. This increase in $q$ is accompanied by to a decrease in the maximum value of $h(t)$ from low to high pitched notes at constant dynamic level. As the dynamic level of the note played decreases the value of the exponent $q$ increases. Again this increase in $q$ corresponds to a decrease in the amplitude of oscillation from loud to quiet notes.

As noted in Section 4.1, the exponent value $q$ does not appear to vary significantly with changes in mouth pressure (and hence sound level) for the experiments carried out with the artificial mouth. There is a trend towards higher $q$ values (up to $q=1.6$ ) for the higher frequency notes investigated with the artificial mouth, and lower $q$ values $(q=1.3)$ for the lower notes, but the range of values of the exponent $q$ is not as great as with the human players. Figure 10 shows results from two notes played using two different embouchures but sounding at the same level $(97 \mathrm{~dB})$. The limited frequency range available with the artificial lips may be one reason why it is not possible to achieve the full range of behaviour seen in the results from the musicians.

It appears that for the musicians at least there is a clear relationship between the amplitude of the lip oscillation and the value of the exponent $q$. As the amplitude decreases, whether it is due to an increase in pitch or a decrease in sound level, there is an increase in the value of the exponent $q$. For the artificial lips the results are less clear. It should however be recalled that a musician changes the 
sound level of a note by simultaneous modifications to the embouchure and blowing pressure. For the experiments with the artificial lips the sound level was changed purely by adjusting the mouth overpressure, without any modification in the embouchure.

\subsection{Lip vibrations with multiple exponent area-height functions}

The hysteresis evident in the some area-height plots is related to asymmetry between the opening and closing parts of the lip vibration cycle. The amount of asymmetry in the cycle and the hysteresis in the area-height plot appears to be inversely related to the value of the exponent $q$. This behaviour is most significant in high amplitude, low pitched notes which have the lowest $q$ values. One of the most striking examples is that given in Figure 11 where two very different slopes are shown. The corresponding plot of open area as a function of time given in Figure 12 is distinctly asymmetrical. The lower slope corresponds to the opening part of the cycle and the upper slope to the part of the cycle in which the lips are closing.

Although a single value of $q$ can provide a good approximation to many cases without significant hysteresis, closer inspection reveals that the gradient of the log-log plot is rarely constant over the full range of amplitudes of opening. In some cases it is clearly necessary to split the cycle into several distinct regions of behaviour.

Figure 13 shows data obtained from one cycle of oscillation for the note $\mathrm{B} b_{1} m f$ from player SK. It can be seen that for the majority of the cycle the width is very close to constant. Inspection of the corresponding log-log plot of area against height (Figure 14) shows that the exponent $q$ is greater than 2 for the opening and closing parts of the cycle, implying that both the width and the mean height are rapidly varying. However over the majority of the cycle the exponent $q$ is close to 1 as the width is effectively constant and the area is linearly related to the mean height.

Figure 15 again shows data from one complete cycle of lip motion, in this case for player TJ playing the note $\mathrm{B} b_{2} m f$. For the opening and closing phases of the lip cycle the exponent $q$ is close to 2 , implying simultaneous variation of width and height; in mid-cycle $q$ is close to 1, implying constant width. These conclusions can be verified by reference to the corresponding plot of area, height and width against time (Figure 16). It can be seen that for the majority of the opening part of the cycle the area, height and width increase steadily. For the mid-cycle part of the motion the area and height are still increasing but the width is almost constant. For the closing part of the cycle the width, area and height are all decreasing. The constant width part is a much smaller fraction of the total cycle for the note $\mathrm{B} b_{2}$ than for the note $\mathrm{B} b_{1}$, an octave lower in pitch.

Similar behaviour is seen in some results from the artificial mouth. Examination of the data in Figure 10 shows that for both of the notes recorded the gradient is close to 1 for values of $h(t)>$ $1 \mathrm{~mm}$.

\section{Conclusion}

A qualitative and quantitative comparison of the time variation of the area, height and width of lip opening of real and artificial lips was given in Section 3. The results show an increase in amplitude of lip motion with increasing sound level and decreasing frequency, with small magnitude variations between human players and between different embouchures on the artificial mouth. The height and 
area of the lip opening vary smoothly over the course of each cycle of oscillation. The width of the opening displays regions of almost constant value at maximum opening, particularly for low pitched loud notes, and less so with increasing pitch or reducing sound level. Although some differences have been identified between the behaviour of the artificial lips and that of the lips of musicians, the general features of behaviour are reproduced by the artificial mouth.

A full investigation of the processes which result in the changes in shape of the lip opening aperture during the course of a cycle would clearly require study and interpretation of the lip dynamics in three dimensions, taking into account the flow-dependent pressures exerted on the lip surfaces at each stage in the vibration. This is beyond the scope of the present paper, which is limited to a study of lip motion in the plane perpendicular to the flow direction.

The original motivation for the present study was to examine whether an exponential area-height function with a single parameter could be used to increase the realism of computer simulations using a single degree of freedom lip model [15]. This possibility was explored in Section 4. Some examples of simple behaviour which can be characterised by a single value of the exponential parameter $q$ have been seen, especially with the artificial lips. In general, however, a single value of $q$ is not sufficient to represent the full detail of the behaviour; frequently two or three distinct regions within a cycle of oscillation are evident, each of which can be fitted using a different value of $q$.

From the playing performance point of view, the exponent $q$ can be seen as a parameter characterizing the brass player's embouchure. The range of possible $q$ values and behaviours illustrates the large variety of embouchures, and consequently the large variety of tone colours, which brass players are able to generate. For example, by manipulating the embouchure, and thereby modifying the $q$ value, the player can control the maximum slope of the mouthpiece pressure waveform. This directly influences the timbre of the played note, and also provides a possible mechanism for controlling the degree of nonlinear propagation, allowing the player to manipulate the radiated brightness at intermediate playing loudness [25]. A change in the area-height function is not, however, the origin of the dramatic increase in the levels of the high harmonics of the radiated sound in very loud 'brassy' playing; this is an inevitable consequence of non-linear propagation [26].

Despite the inevitable differences in technique and style between the five players studied, some general trends emerged from the measurements on human players. As the amplitude of the lip oscillation decreased, whether due to an increase in pitch or a decrease in sound level, there was an increase in the value of the exponent $q$. The results from the artificial lips showed a similar relationship for variations in pitch; however changes in sound level had relatively little effect on the exponent $q$. For mid range notes played $m f$, the values of $q$ for human players and the artificial mouth were broadly in agreement. These trends are illustrated by Figure 17. Thus, while the full complexity of the lip motion in a human player cannot be captured by a single degree of freedom model, the results of the present study suggest that the realism of simulations of trombone playing using such a model can be improved by using an exponential area-height function with parameter values similar to those shown in Figure 17.

\section{Acknowledgments}

This work was supported by a Doctoral Training Grant from the U.K. Engineering and Physical Sciences Research Council. The authors wish to thank Mathieu Chekroun, Orlando Richards, 
Sam Stevenson and Michael Newton for valuable discussions and experimental assistance, Timothy Jones, Alistair Justice and Sunil Kamath for taking part in the performance experiments, and the two referees for their helpful comments.

\section{References}

[1] D.W. Martin: Lip vibrations in a cornet mouthpiece. J. Acoust. Soc. Am. 13 (1942) 305-308.

[2] D.C. Copley, W.J. Strong: A stroboscopic study of lip vibrations in a trombone. J.Acoust.Soc.Am. 99 (1996) 1219-1226.

[3] C. Vergez, X. Rodet: Experiments with an artificial mouth for a trumpet. Proc. ICMC 98, 153-158, 1998.

[4] S. Yoshikawa, Y. Muto: Lip-wave generation in horn players and the estimation of lip-tissue elasticity. Acustica united with acta acustica 89 (2003) 145-162.

[5] S.J. Elliott, J.M. Bowsher: Regeneration in brass wind instruments. J. Sound Vib. 83 (1982) 181-217.

[6] J. Gilbert, S. Ponthus, J.F. Petiot: Artificial buzzing lips and brass instruments: Experimental results. J. Acoust. Soc. Am. 104 (1998) 1627-1632.

[7] J.S. Cullen, J. Gilbert, D.M. Campbell: Brass instruments: linear stability analysis and experiments with an artificial mouth. Acustica united with acta acustica 86 (2000) 704-724.

[8] M.A. Neal: A study of the brass instrument lip reed mechanism using artificial lips and lattice Boltzmann flow simulations. PhD thesis, The University of Edinburgh, 2002.

[9] O. Richards: Investigation of the lip reed using computational modelling and experimental studies with an artificial mouth. PhD thesis, The University of Edinburgh, 2003.

[10] A. Hirschberg, J. Kergomard, G. Weinreich (eds): Mechanics of musical instruments, Springer Verlag 1995.

[11] H.J.F. Helmholtz: On the sensation of tone, 1877. Translated by A.J. Ellis, reprinted by Dover, 1954.

[12] N. H. Fletcher: Excitation mechanisms in woodwind and brass instruments. Acustica 43 (1979) 63-72.

[13] N.H. Fletcher: Autonomous vibration of simple pressure-controlled valves in gas flows. J. Acoust. Soc. Am. 93 (1993) 2172-2180.

[14] N. Amir, V. Pagneux, J. Kergomard: A study of wave propagation in varying cross-section waveguides by modal decomposition. Part II: results. J. Acoust. Soc. Am. 101 (1997) 25042517.

[15] J. Gilbert, S. Bromage, M. Campbell: Influence of the open area of a player's lips on brass instrument behaviour. Proc. Forum Acusticum Budapest 2005. 
[16] A.H. Benade: Fundamentals of musical acoustics. Oxford University Press, 1976.

[17] J. Gilbert: Etude des instruments de musique à anche simple. $\mathrm{PhD}$ thesis, Université du Maine, Le Mans, 1991.

[18] J.P. Dalmont, J. Gilbert, S. Ollivier: Nonlinear characteristics of single reed instruments: quasistatic volume flow and reed opening measurements. J. Acoust. Soc. Am. 114 (2003) 22532262.

[19] A. Barjau, J. Agulló: Calculation of the starting transients of a double-reed conical woodwind. Acustica 69 (1989) 204-210.

[20] A. Almeida, C. Vergez, R. Caussé: Experimental investigation of reed instrument functioning through image analysis of reed opening. Acta Acustica united with Acustica 93 (2007) 645658 .

[21] R. Msallam, S. Dequidt, R. Caussé, S. Tassart: Physical model of the trombone including nonlinear effects. Application to sound synthesis of loud tones. Acustica united with acta acustica 86 (2000) 725-736.

[22] R.D. Ayers: New perspectives on brass instruments. Proc. ISMA 98, Leavenworth 1998.

[23] Vision Research Inc: http://www.visiblesolutions.com. Accessed 30th July 2009.

[24] S.D.F. Stevenson: Experimental Investigations of Lip Motion in Brass Instrument Playing. Ph.D. Thesis, The University of Edinburgh, 2009.

[25] L. Norman, J.P. Chick, D.M. Campbell, A. Myers, J. Gilbert: Player control of 'brassiness' at intermediate dynamic levels in brass instruments. Submitted to Acta Acustica united with Acustica.

[26] S. Stevenson, M. Campbell, S. Bromage, J. Chick, J. Gilbert: Motion of the lips of brass players during extremely loud playing. J. Acoust. Soc. Am. 125 (2009) EL152-157. 


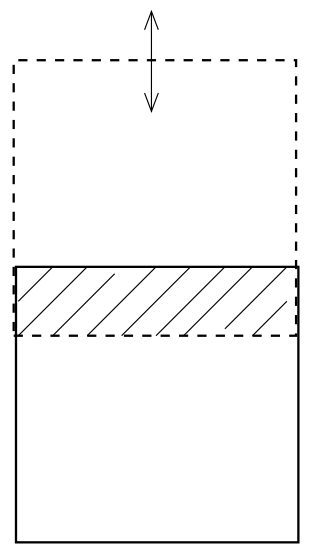

(a)

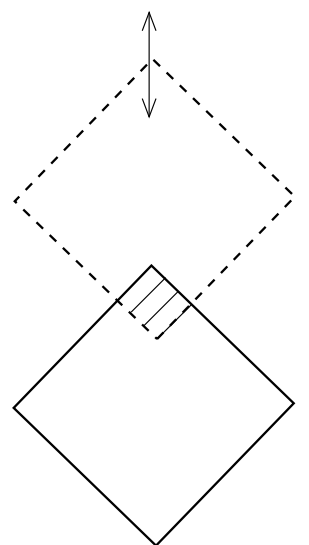

(b)

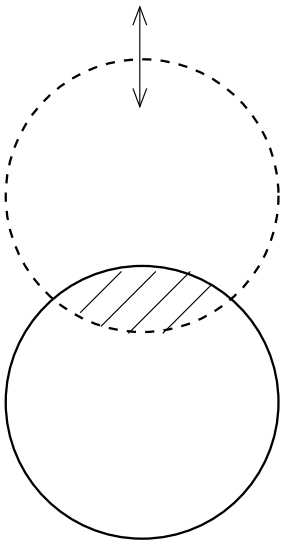

(c)

Figure 1: Three illustrations of opening areas (from left to right): (a) a "moving rectangular" area (the overlap of two rectangles), (b) a "moving diamond" area (the overlap of two diamonds, (c) a "moving circle" area (the overlap of two circles). 


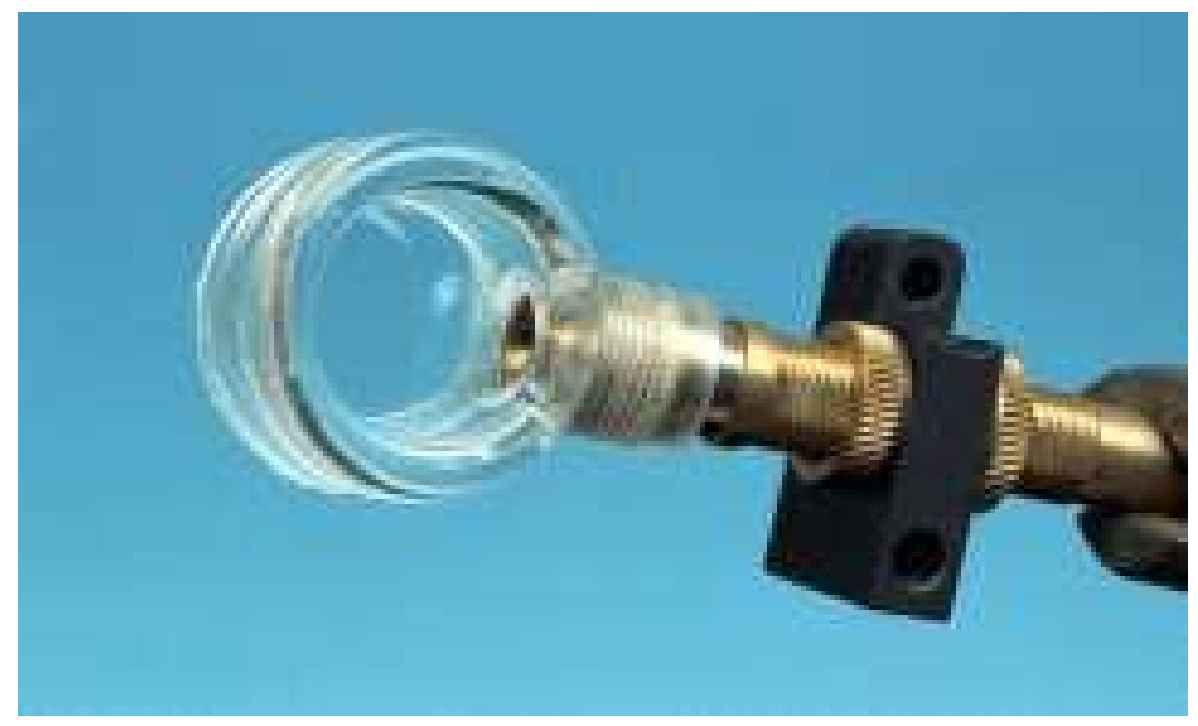

Figure 2: Transparent mouthpiece for trombone 

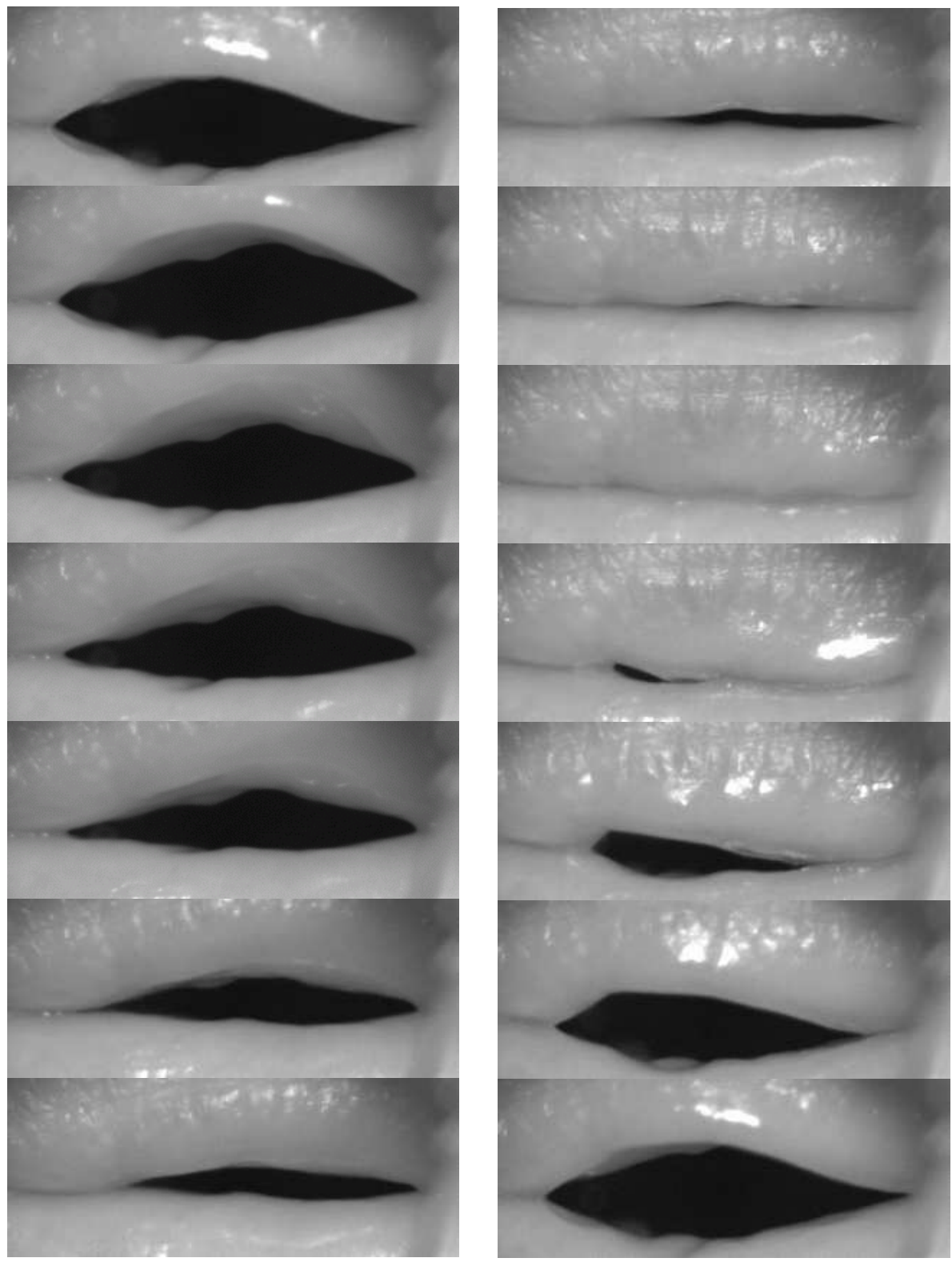

Figure 3: Example images from one cycle of lip vibration, player MC 


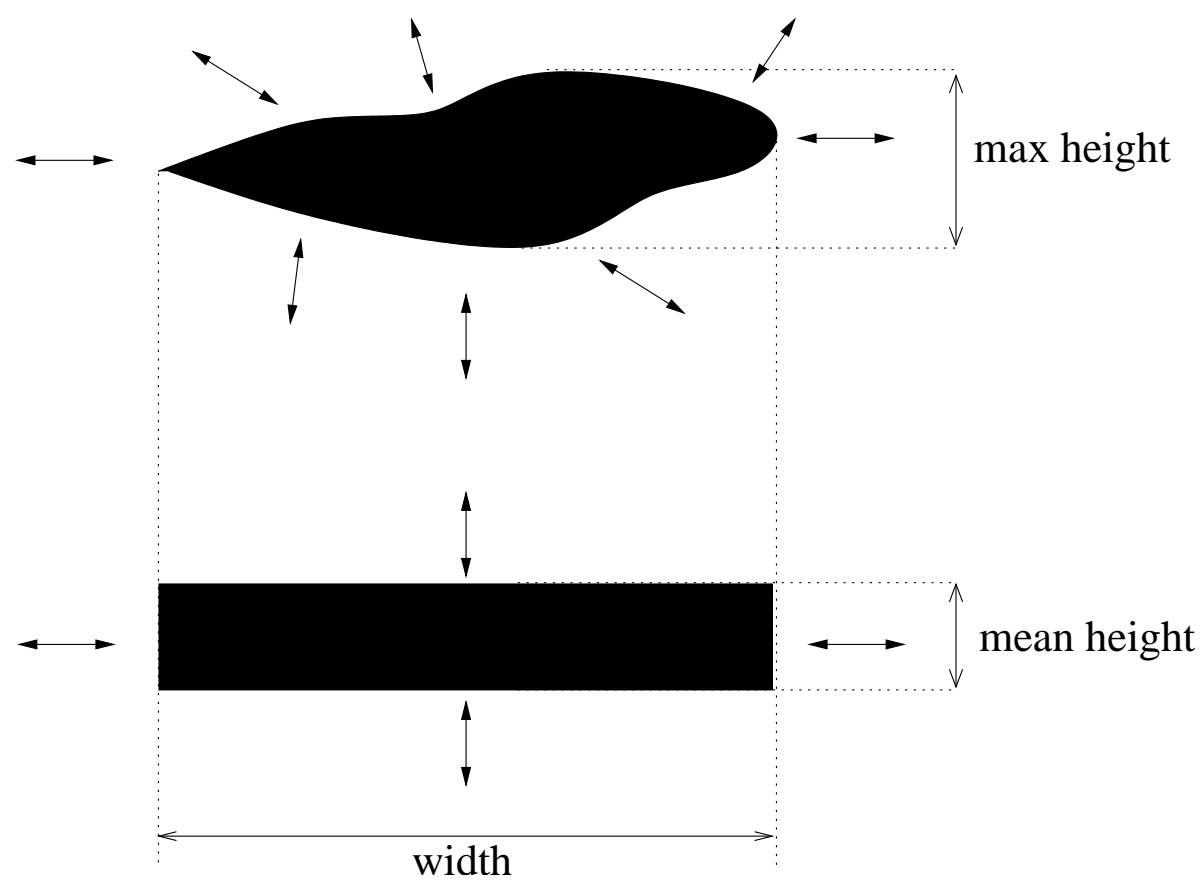

Figure 4: Illustration of simplification of a complicated shape where different sections of the lips are moving in different ways to a rectangle of time varying width and height. 


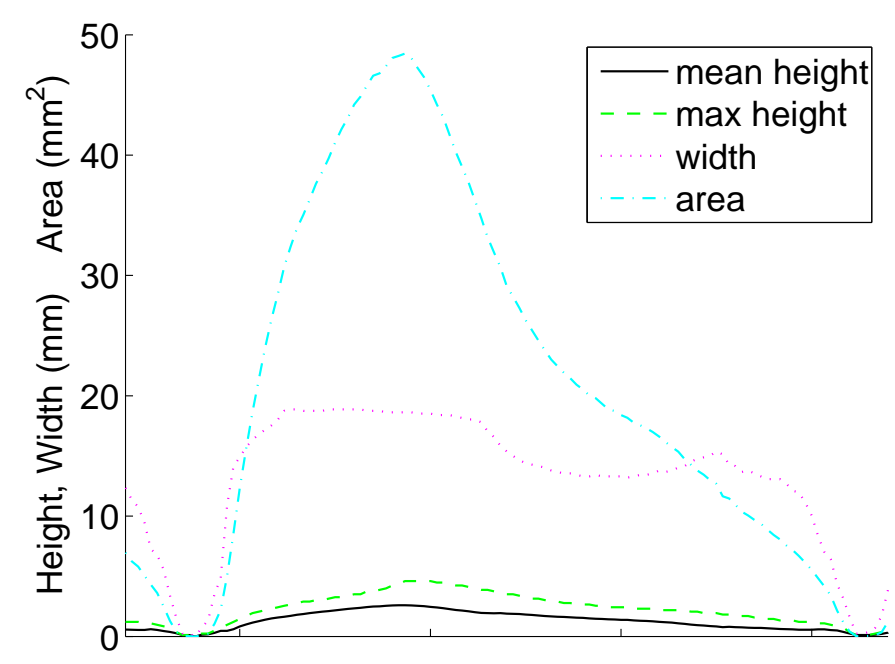

(a)

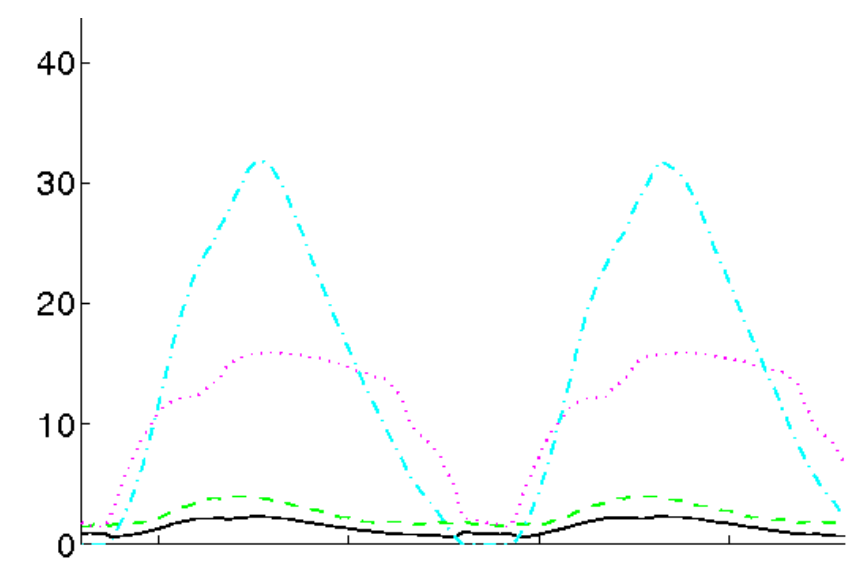

(b)

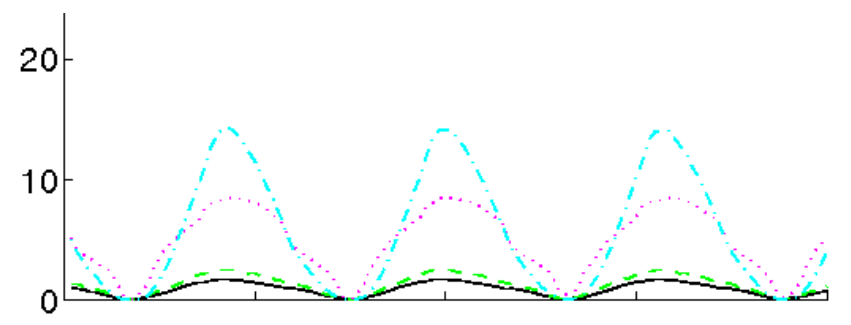

(c)

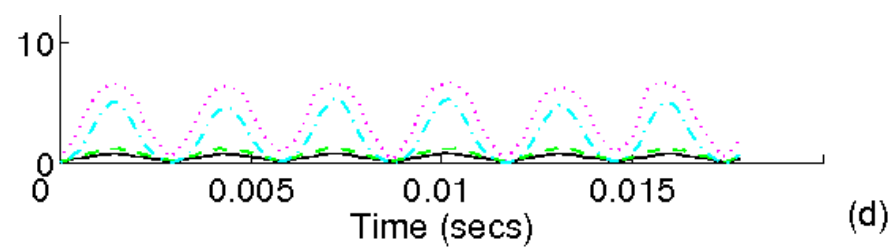

Figure 5: Lip opening area, height and width as a function of time: player AJ, notes (a) $\mathrm{B} b_{1} m f$, (b) $\mathrm{B} b_{2} m f$, (c) $\mathrm{F}_{3} m f$, (d) $\mathrm{F}_{4} m f$. 

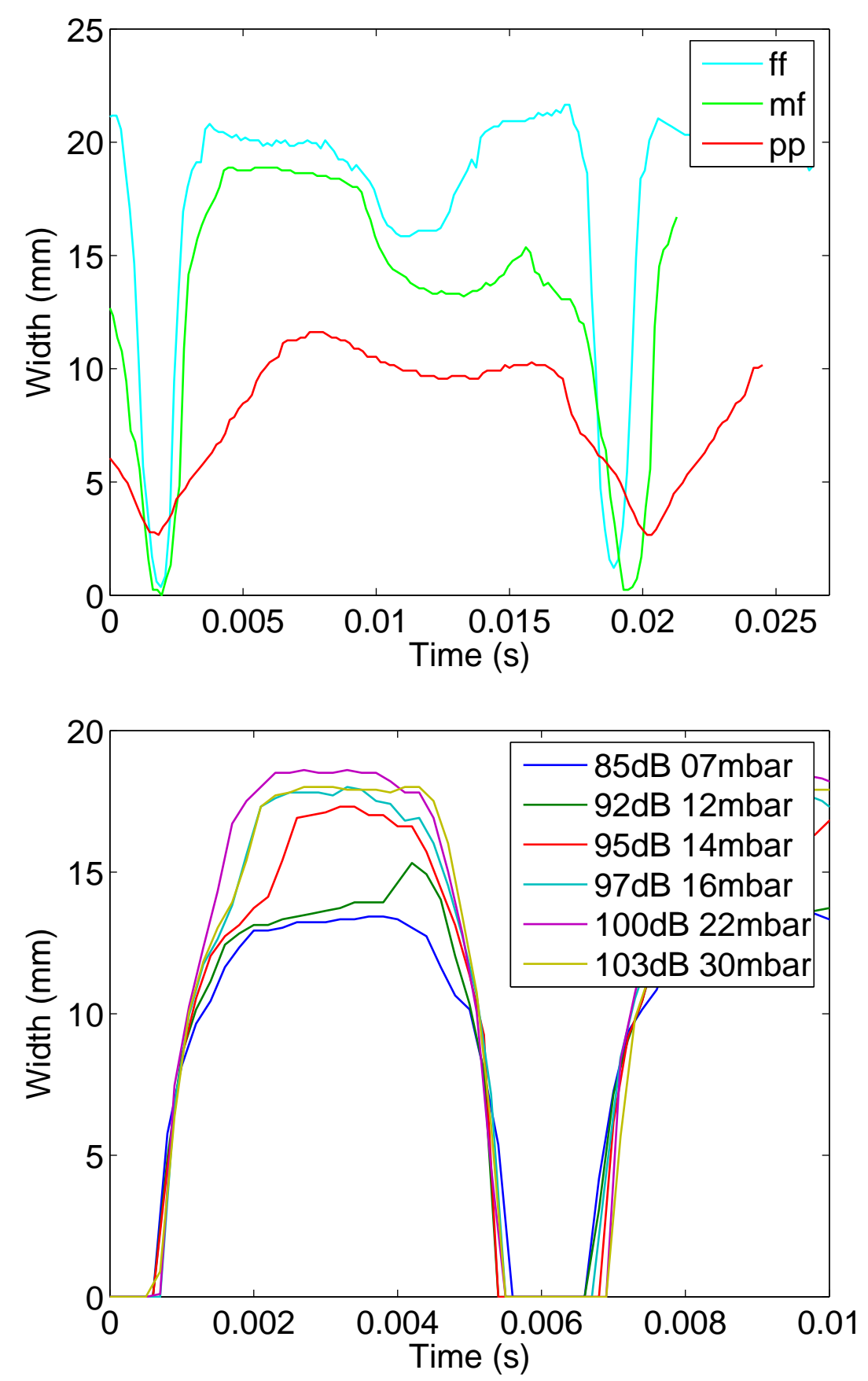

Figure 6: Lip opening width as a function of time at different dynamic levels. Above: player AJ, note $\mathrm{B} b_{1}$. Below: artificial mouth, note $\mathrm{E}_{3}$; inset box gives radiated sound pressure level and mouth pressure 

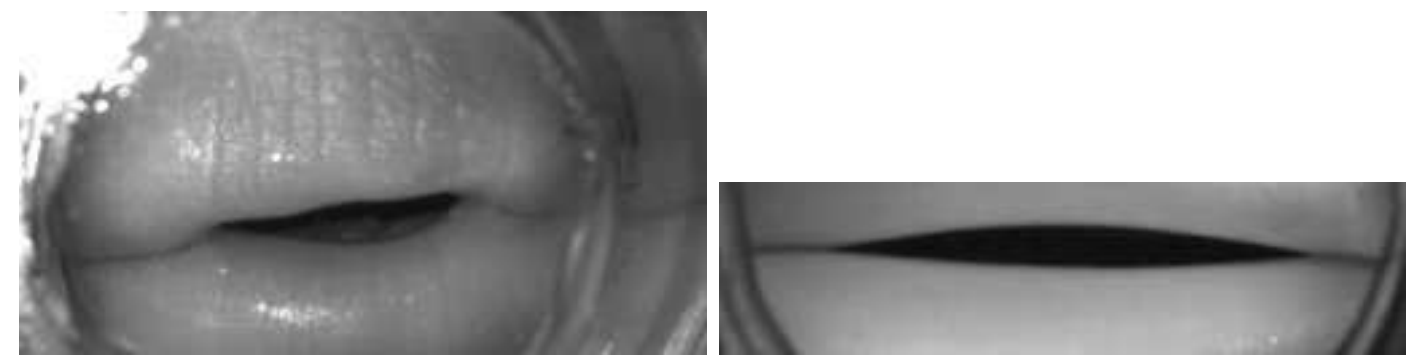

Figure 7: Maximum width of the opening of the lips of (left) player TJ playing the note $\mathrm{B}_{2}$ at $m f$ and (right) the artificial mouth playing note $\mathrm{E}_{3}$ at $97 \mathrm{~dB}$ 


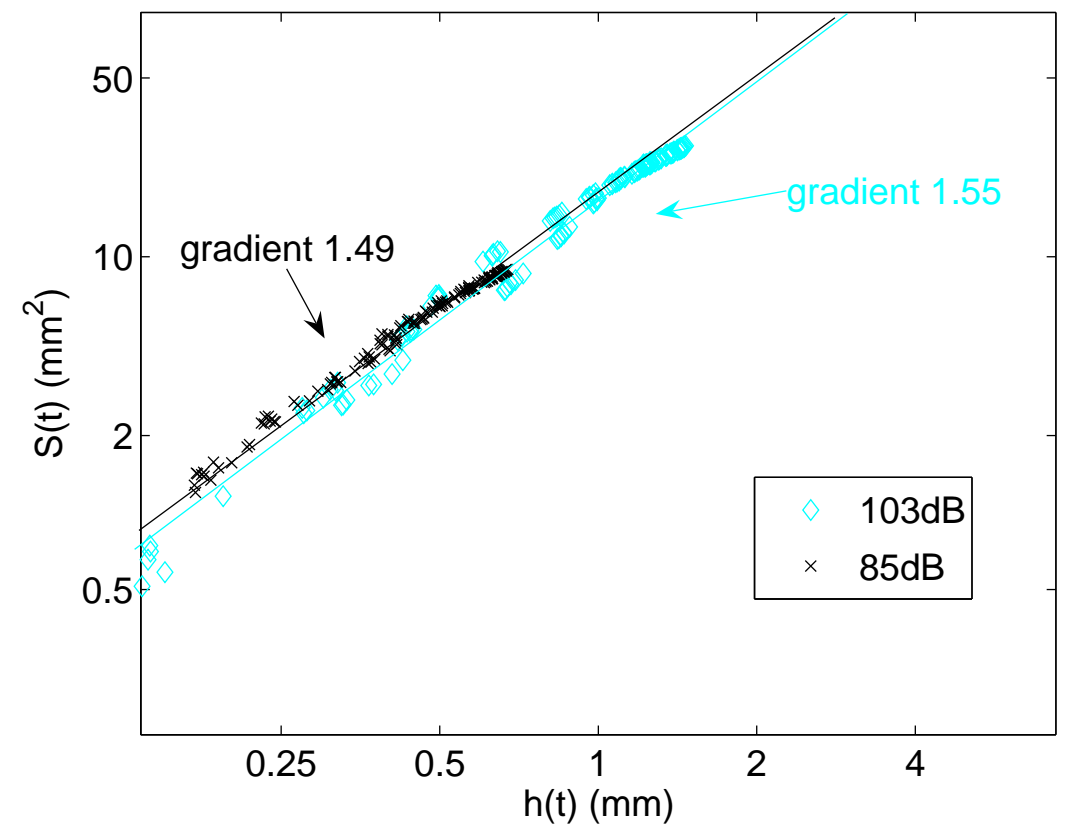

Figure 8: Logarithmic area-height plot for artificial lips playing the note $\mathrm{E} 3$ at $85 \mathrm{~dB}$ and $103 \mathrm{~dB}$ 

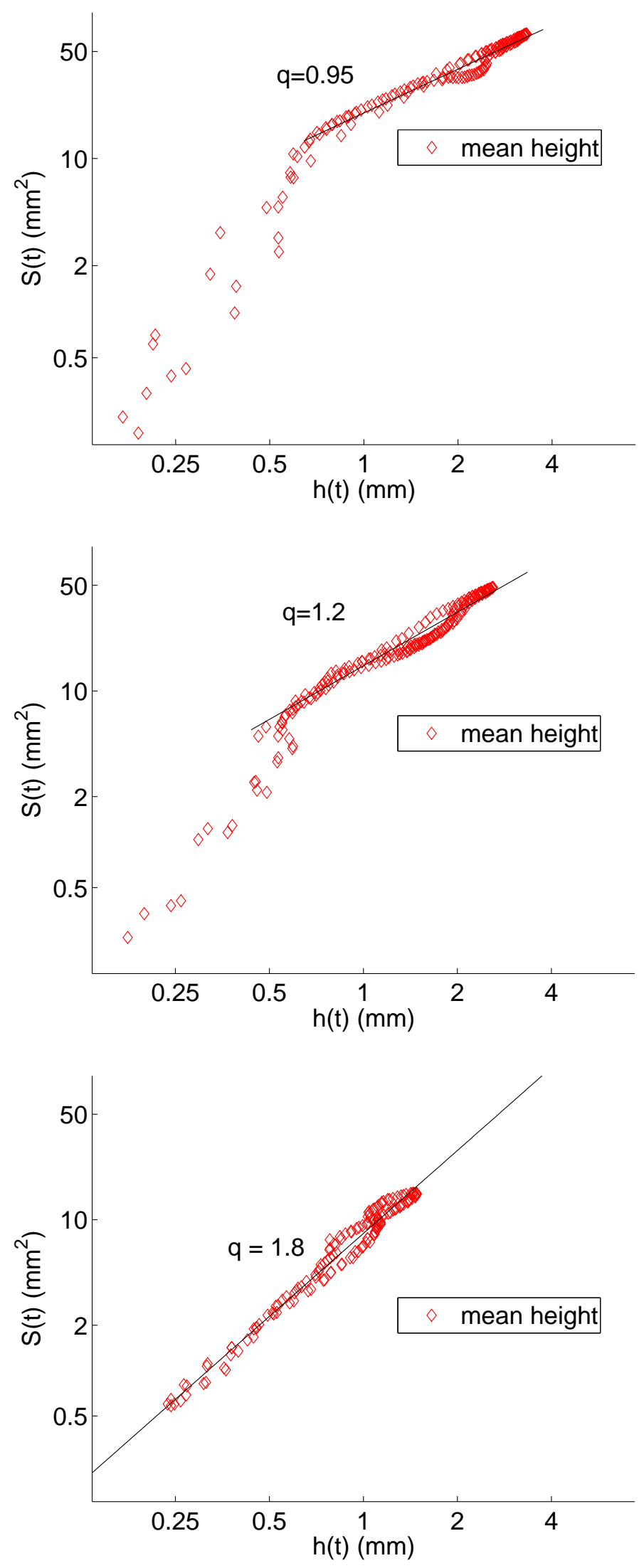

Figure 9: Logarithmic area-height plot for player $\mathrm{AJ}$, note $\mathrm{B} b_{1}$, dynamic levels (from top down ) ff, $m f, p$. 


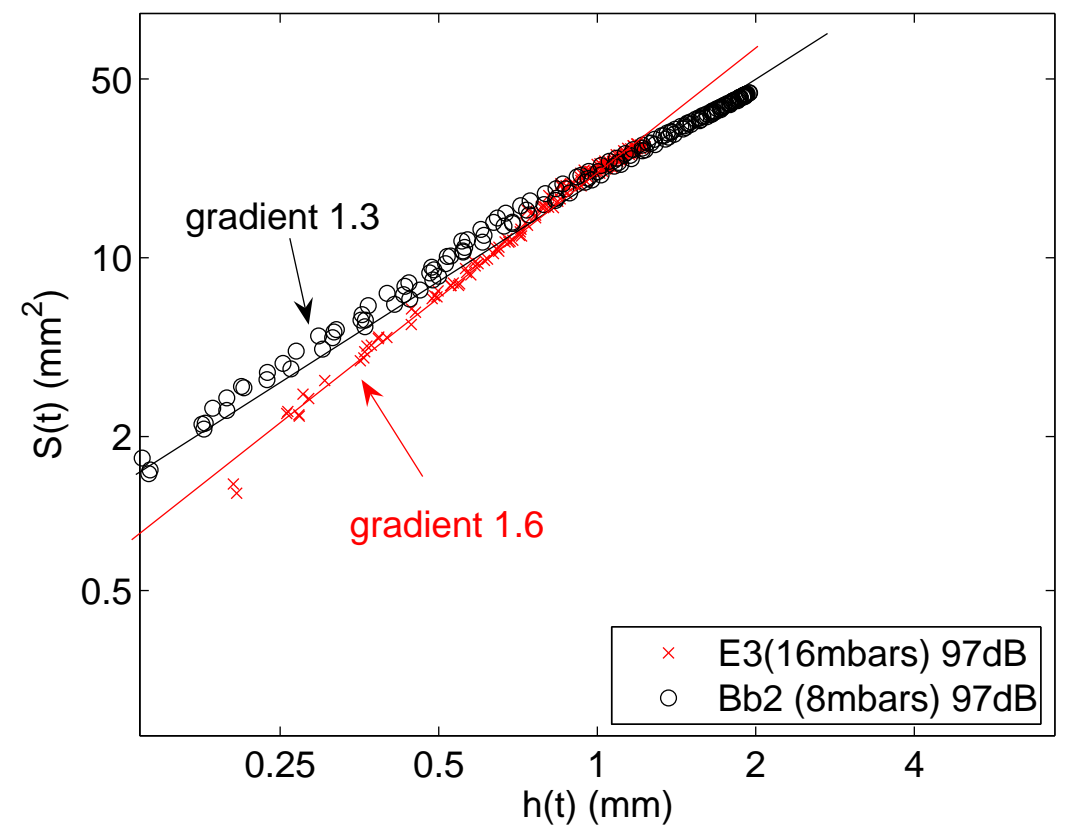

Figure 10: Logarithmic area-height plot for artificial lips, notes $\mathrm{B} b_{2}$ and $\mathrm{E}_{3}$ at $97 \mathrm{~dB}$. 


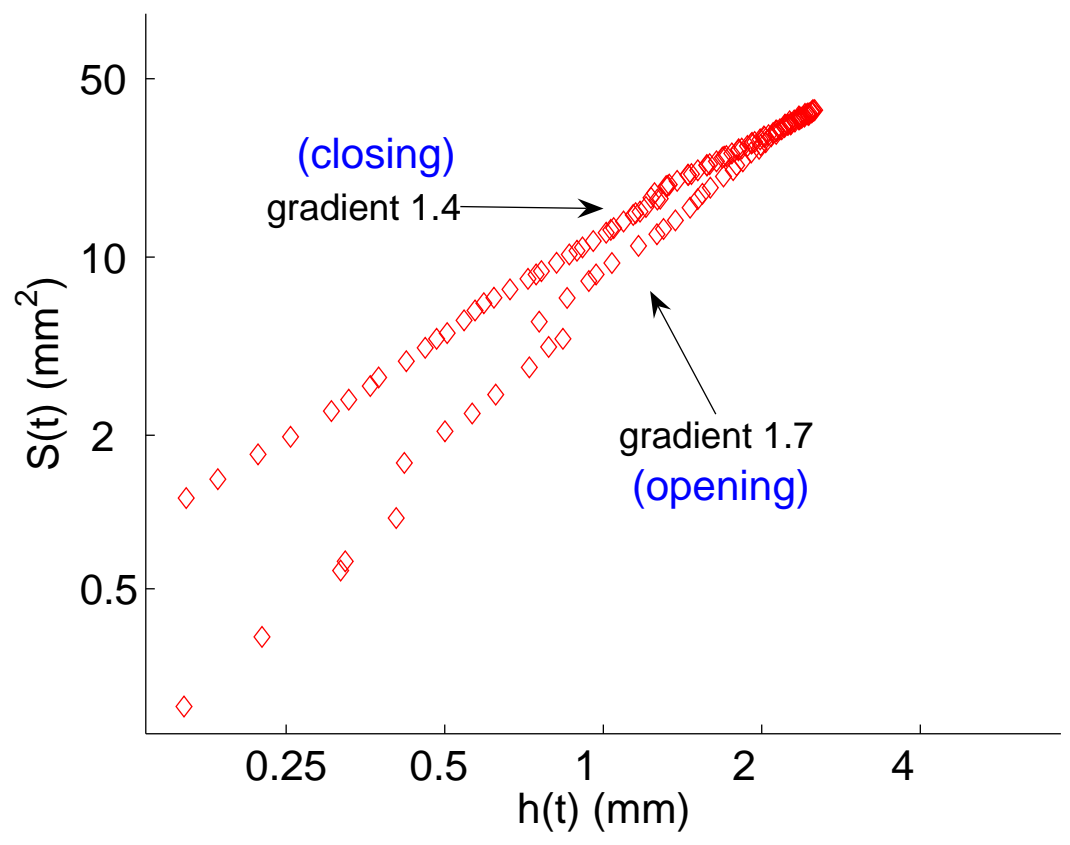

Figure 11: Logarithmic area-height plot for player $\mathrm{MC}$, note $\mathrm{A}_{1} p$. 


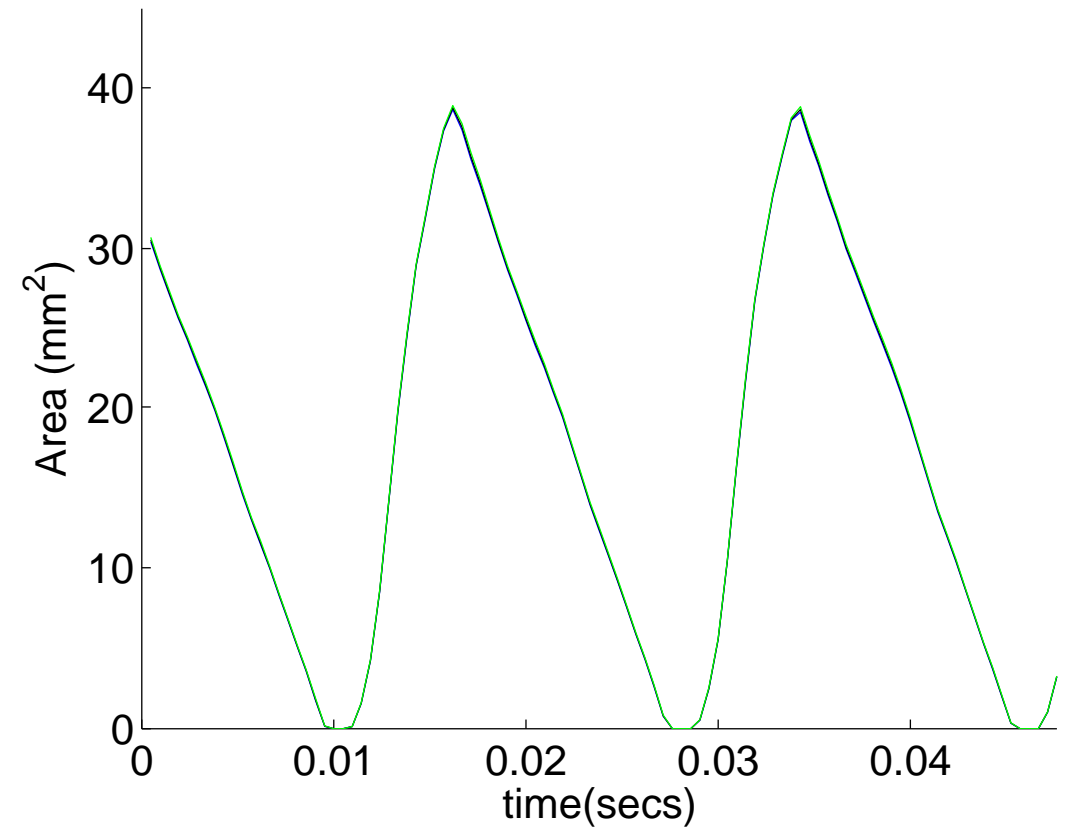

Figure 12: Lip opening area as a function of time for player $\mathrm{MC}$, note $\mathrm{A}_{1} p$. 


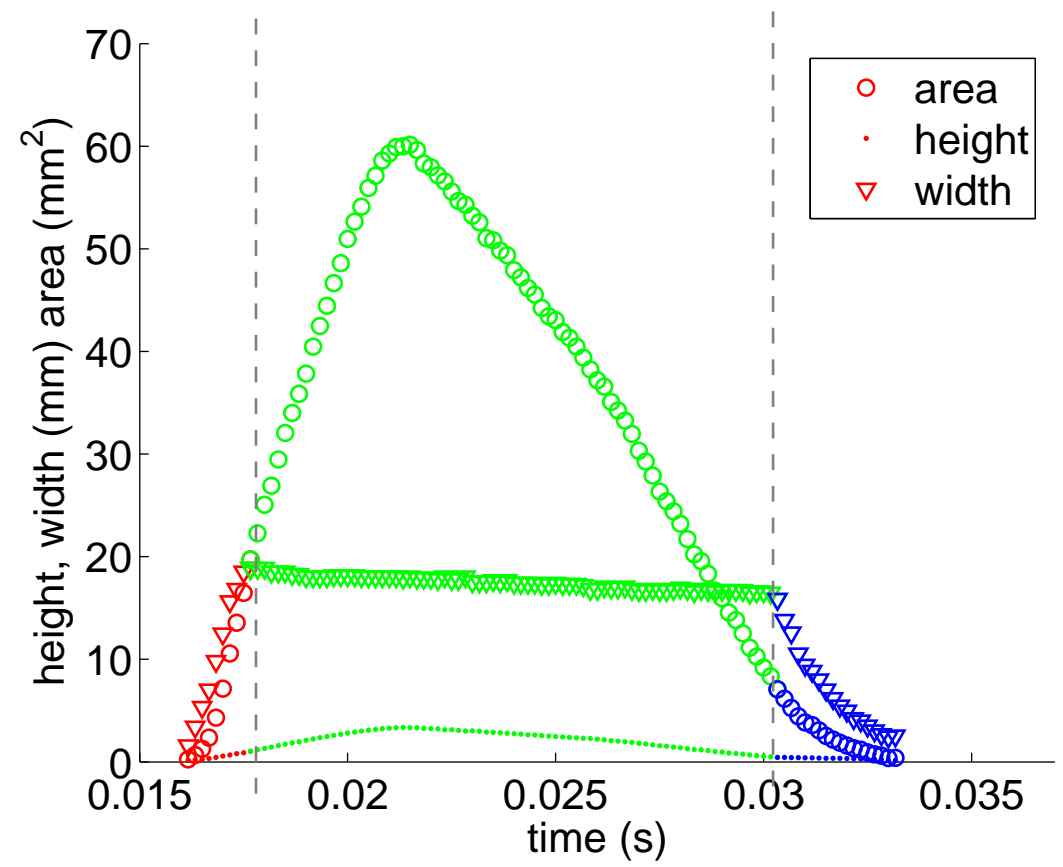

Figure 13: Area, mean height and width as a function of time for player SK, note $\mathrm{B} b_{1} m f$. 


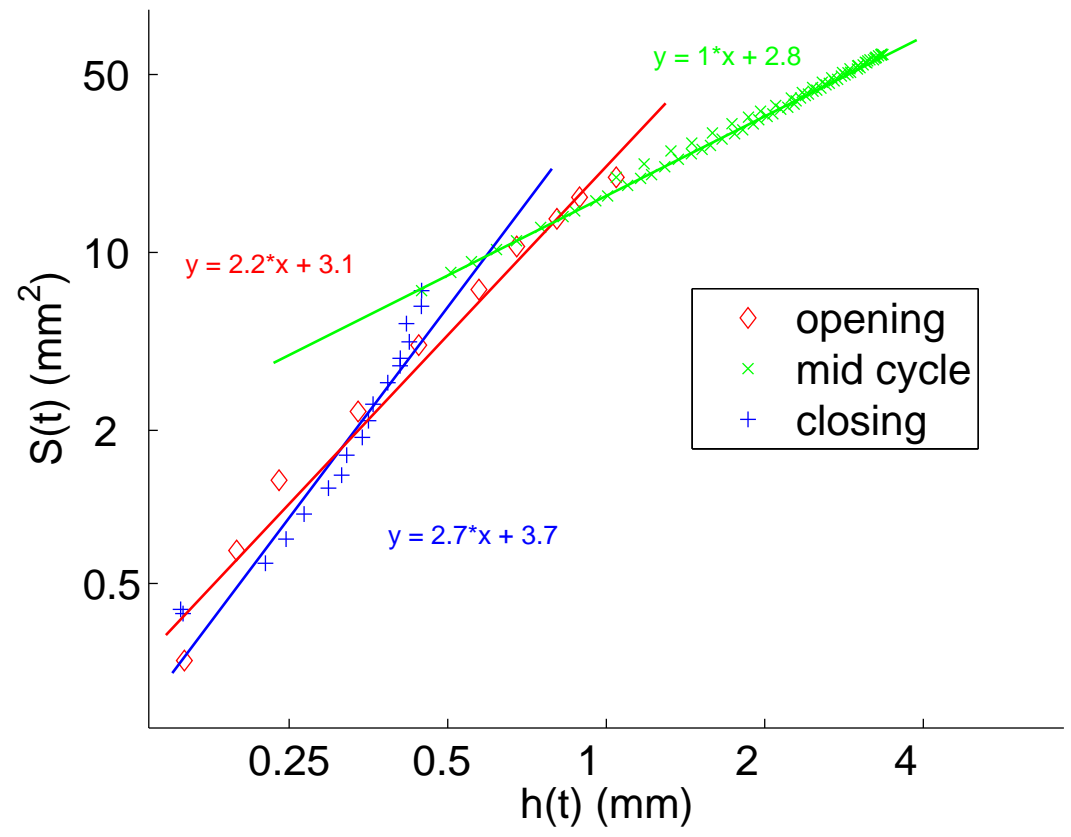

Figure 14: Logarithmic area-height plot for player SK, note $\mathrm{B} b_{1} m f$. The three data sets correspond to different parts of the cycle (opening, mid-cycle, and closing). 


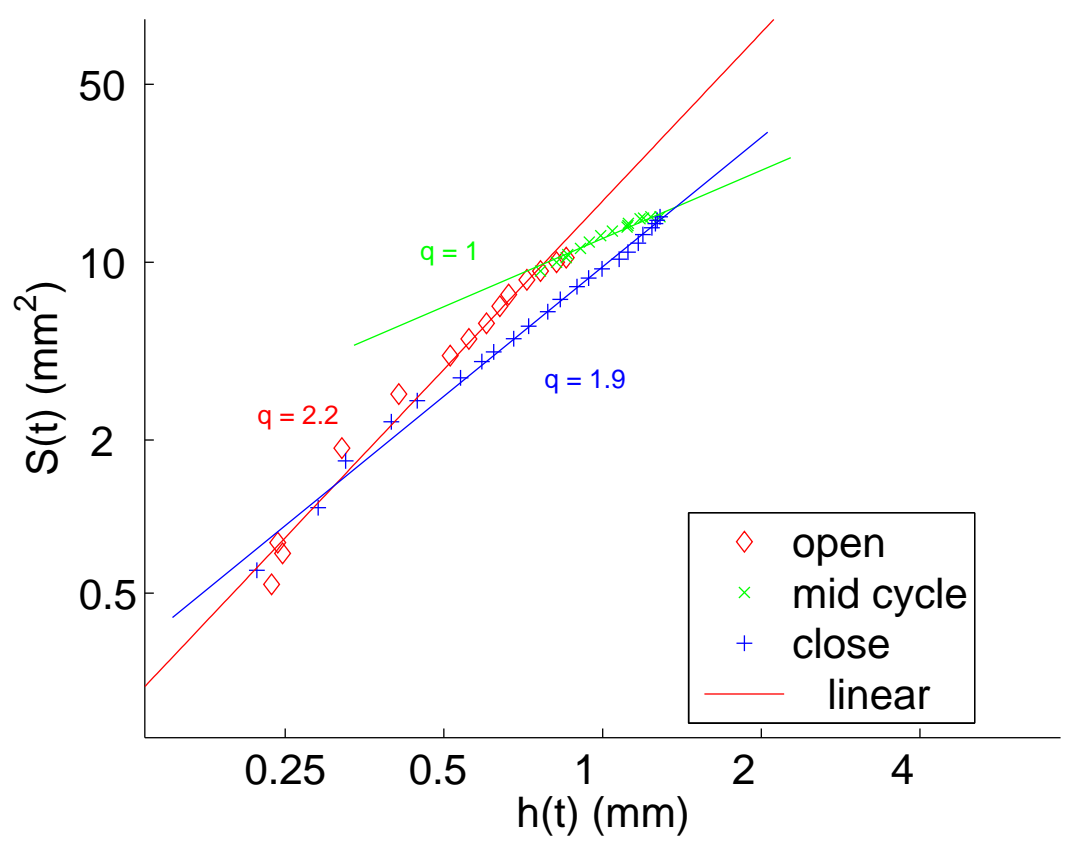

Figure 15: Logarithmic area-height plot for player $\mathrm{TJ}$, note $\mathrm{B} b_{2} m f$. The three data sets correspond to different parts of the cycle (opening, mid-cycle, and closing). 


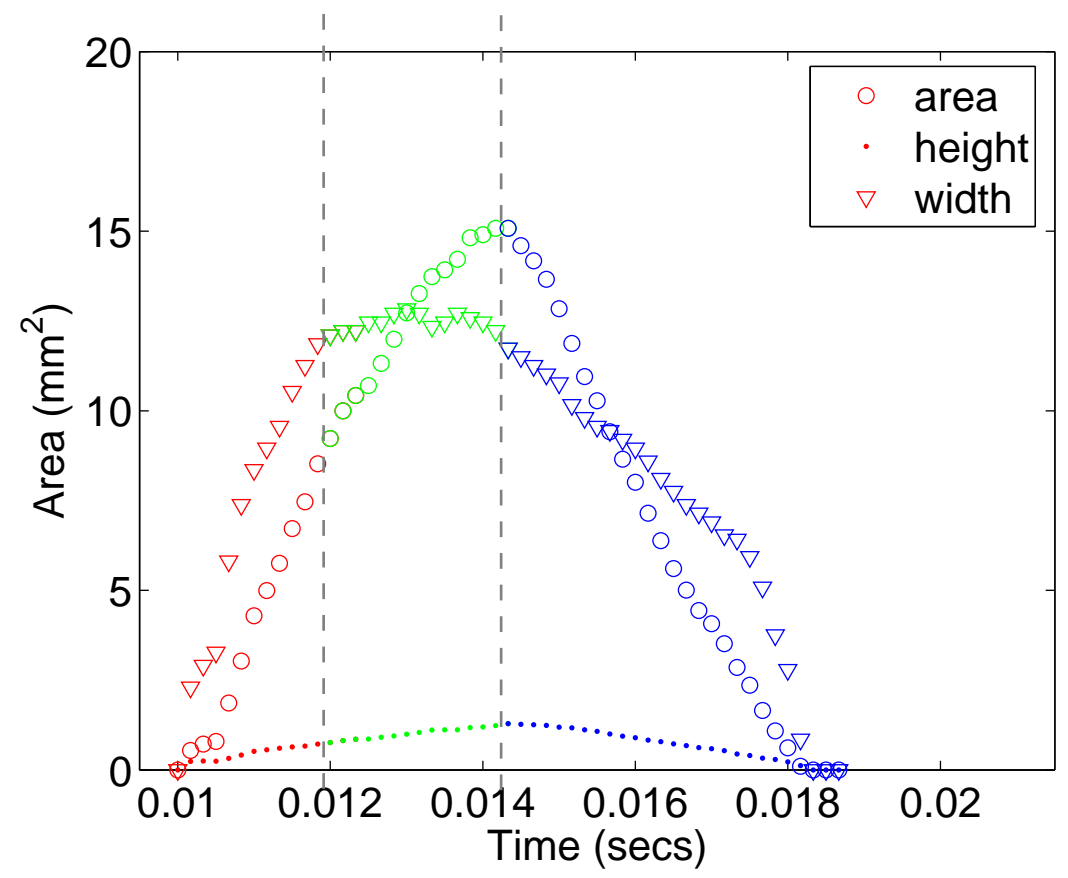

Figure 16: Area, mean height and width as a function of time for player $\mathrm{TJ}$, note $\mathrm{B} b_{2} m f$. 


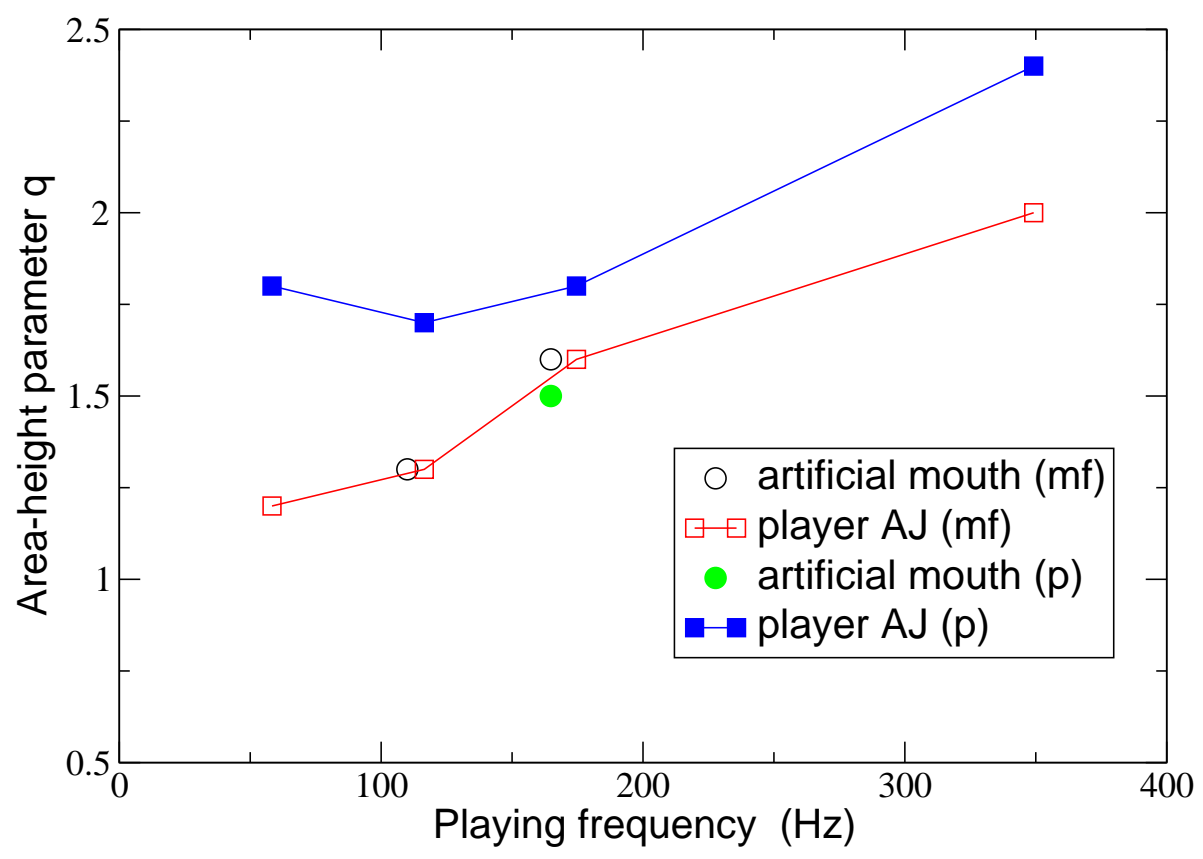

Figure 17: Area-height parameter $q$ as a function of playing frequency for dynamic levels $p$ and $m f$. Squares: player A; circles: artificial mouth 